Las circunstancias derivadas de la sucesión presidencial de 1920, en especial la decisión del presidente Carranza de imponer un sucesor civil contra las ambiciones del general Álvaro Obregón, se tradujeron desde temprano en un progresivo distanciamiento entre Adolfo de la Huerta y su antiguo jefe. Muy a su pesar, según lo diría aquél en repetidas ocasiones, asumió el papel que le correspondió en la liquidación del régimen carrancista y la construcción de uno nuevo, el de la llamada hegemonía sonorense. Puesto en el frente político de la revuelta iniciada en Agua Prieta, Sonora, y respaldado por un alzamiento militar encabezado por su amigo y colaborador Plutarco Elías Calles, Adolfo de la Huerta acabaría sucediendo a Carranza, para luego entregar el poder al general Álvaro Obregón. Para la mayoría de los observadores del proceso, el círculo se cerraba de esta manera. Obregón, sin mayor trámite, era el cerebro de toda la operación y al fin veía realizados sus deseos de llegar a la presidencia. En esta interpretación, el papel de De la Huerta estaba limitado a ser el de una suerte de mandatario de transición, cuya figura disminuía en la medida en que su sucesor abarcaba el espacio político a partir de la cúspide del poder. Por lo demás, la oposición de don Venustiano a que Obregón llegase a la presidencia, la cerrada alianza sonorense en favor de este último, los preparativos de insurrección nacional ante un posible fracaso obregonista en las elecciones, con frecuencia pusieron al antiguo presidente municipal de Huatabampo en el centro de la rebelión de Agua Prieta. El movimiento se inició, en efecto, teniendo el partidarismo del grupo Sonora en beneficio de Obregón como telón de fondo y culminando en su beneficio político. Y, sin embargo, a pesar de las circunstancias y de una idea asumida como definitiva por historiadores del periodo, no se conocen evidencias sólidas y contundentes de las maquinaciones de Obregón que den fundamento a una tesis conspirativa, en términos de haber sido él quien instigó la insurreción tras bambalinas. Tres circunstancias lo impedían: la pre-

\footnotetext{
* Maestro en sociología política. Profesor de la Universidad Autónoma Metropolitana Iztapalapa. Autor de Adolfo de la Huerta y la Revolución mexicana.
} 
electo Primer Jefe el entonces gobernador de Coahuila. Éste fue el primero de muchos contactos personales y de trabajo entre ellos. En reconocimiento a sus servicios, y a su creciente relevancia política, el 15 de septiembre de 1913, fue nombrado oficial mayor de la Secretaría de Gobernación, subordinado al subsecretario Eliseo Arredondo. ${ }^{1}$ Y para el 19 de mayo de 1916, De la Huerta fue nombrado por Carranza gobernador interino de su estado natal, en sustitución del general Plutarco Elías Calles, hasta el 1 de septiembre de $1917 .^{2}$

Durante su gobierno, y "siguiendo fielmente las instrucciones del señor Carranza”, el gobernador De la Huerta puso en marcha una serie de medidas de corte reformista en los campos agrario y obrero, que le valieron acusaciones de ser radical. ${ }^{3}$ A través de la Comisión Local Agraria y el Departamento de Agricultura, Tierras y Aguas, restituyó 67773 hectáreas de terreno "cultivado, por una parte, por el establecimiento de Cooperativas Agrícolas, y en otras por la creación de la pequeña propiedad, y el resto por el uso y goce comunal concedido a los pueblos y congregaciones". 4 Por otro lado, el establecimiento de la Cámara Obrera y sus decretos en materia de trabajo, ${ }^{5}$ así como su iniciativa llevada al Congreso Constituyen-

\footnotetext{
1 "Memo for De la Huerta", cuestionario sin fecha, presuntamente aplicado por el Departamento de Justicia de los Estados Unidos, durante el proceso para conceder asilo político a De la Huerta, respuesta 16, en Archivo Familia de la Huerta (AFDH). Este documento, de gran importancia por su valor testimonial, será citado en adelante como $M / D r H$. Antonio Rivera, La Revolución en Sonora, México, Edición del Autor, 1969, p. 322-325. José C. Valadés, Las memorias de don Adolfo de la Huerta, expresidente de México: memorias de doce años de política revolucionaria en México, 1911.1923, edición privada de 50 ejemplares, Mérida, Talleres de la Compañía Tipográfica Yucateca, 1930, p. 20-22.

${ }^{2}$ Héctor Aguilar Camín, La frontera nómada: Sonora y la Revolución mexicana, México, Siglo XxI, 1979, p. 423; Rivera, op. cit., p. 477-480.

${ }^{3}$ Las disposiciones en materia obrera "fueron derogadas por su sucesor [Calles], por considerarlas en esa época demasiado radicales". Adolfo de la Huerta, Resumen biográfico del Sr. Adolfo de la Huerta, p. 3, en AFDH; Intelligence Report, National Archives of the United States (NAW), Militar Intelligence Division (MID), October 12, 1916, p. 640-772. Estos informes serán citados en adelante con las siglas NAW/MID, Chicago Labor News (July 21, 1916); iinda Hall, Álvaro Obregón: poder y revolución en México, 1911-1920, México, FCE, 1985, p. 187.

${ }^{4} \mathrm{M} / \mathrm{HL}$, p. 2; Adolfo de la Huerta, Informe que rinde al $\mathrm{H}$. Congreso del Estado, el gobernador provisional de Sonora, por el periodo de su gobierno, comprendido entre el 19 de mayo de 1916 y el 18 de junio de 1917, Hermosillo, Imprenta del Gobierno del Estado, 1917, p. 9.

${ }^{5}$ La Cámara Obrera contaba con un delegado por cada mil trabajadores. Este cargo sería ejercido por un año, con un sueldo de diputado. Este órgano podía conocer las quejas y violaciones a las leyes laborales, debía proponer formas de mejoramiento de la organización obrera estatal, externar juicios periciales sobre indemnizaciones por accidentes de trabajo, proponer soluciones a conflictos obrero-patronales, sugerir candidatos para los puestos de inspectores de higiene y seguridad en las fábricas, promover leyes concernientes a su ramo y dar audiencia a los representantes patronales. Aguilar Camín, op. cit., p. 439, y Rivera, op. cit., p. 482-484. Por otra parte, el decreto 71 del 16 de octubre de 1916 también incluía el establecimiento de ocho horas de trabajo como jornada máxima, la edad y el salario mínimos, el descanso semanal obligatorio, la exigencia a las empresas de contrato escrito para trabajos de
} 
te de Querétaro, lo ubicaron en el ala radical del constitucionalismo. De la Huerta siempre declaró ser el autor intelectual de las fracciones VI y IX del artículo 123 de la Constitución Política de 1917, que sostenían el principio de que los trabajadores debían tener participación en las utilidades de las empresas donde laboraban. Bojórquez deja constancia de que De la Huerta lo instruyó a él, a Froylán C. Manjarrez y a Flavio A. Bórquez, que sometieran a la asamblea el proyecto que culminó, efectivamente, con la redacción de tales fracciones. ${ }^{6}$

Al abandonar la gubernatura en septiembre de 1917, De la Huerta fue electo senador por su estado, pero sirvió solamente unos cuantos meses porque el presidente Carranza lo llamó a desempeñar importantes comisiones políticas. ${ }^{7}$ En un primer momento, le pidió que aceptase el puesto de gobernador de Yucatán para suceder al general Salvador Alvarado. El ilimitado poder de Alvarado en Yucatán se encontraba en franca decadencia hacia el fin del periodo preconstitucional y del sistema de comandancias militares; en cambio, el gobierno civil y la política electoral partidista se robustecían al cobijo de las normas de la nueva constitución mexicana de 1917. Alvarado había buscado infructuosamente sucederse a sí mismo en la gubernatura, y con este propósito en octubre de 1916 externó su intención de participar como civil en las elecciones de noviembre de 1917. Poco después, fue declarado residente oficial de Yucatán y solicitó una licencia como comandante militar de la región. No obstante, el hecho de no haberse domiciliado en el estado durante un mínimo de cinco años seguidos, de acuerdo con la constitución local, y la renuencia de Carranza a apoyarlo en este intento, lo sacó del camino. A mediados de 1917, Alvarado fue nombrado jefe de las operaciones militares en el sudoriente de México y se le ordenó que supervisara las operaciones carrancistas en Chiapas, Tabasco y el Istmo de Tehuantepec. A partir de entonces, y hasta noviembre, cuando Alvarado abandonó el cargo, estuvo prácticamente ausente del estado. Pero antes de marcharse, dejó varios legados: una constitución estatal que incorporaba sus reformas, la divi-

más de seis días y la indemnización por accidentes de trabajo. Más adelante, en virtud del decreto 92 del 30 de marzo de 1917, se reglamentó el trabajo en el estado "sobre bases equitativas y de acuerdo con las ideas de la Revolución", y por el decreto 97 del 16 de julio del mismo año, se puso en marcha la Ley sobre Indemnizaciones por Accidentes Sufridos en el Trabajo. De la Huerta, Informe..., op. cit, p. 9; Hall, op. cit., p. 186-187; Rivera, op. cit., p. 484.

${ }^{6}$ Juan de Dios Bojórquez, Forjadores de la Revolución mexicana, México, Publicaciones del Instituto Nacional de la Revolución Mexicana, 1960, p. 64.

${ }^{7}$ Entrevista al ingeniero Arturo de la Huerta, Guaymas, Son., 20 de octubre de 1994. De la Huerta, Resumen biográfico..., op. cit., p. 4. 
sión del poder civil del estado, antes unificado durante su gobierno militar, así como su apoyo a la candidatura de Carlos Castro Morales a gobernador y a Felipe Carrillo Puerto como nuevo jefe del Partido Socialista Yucateco. ${ }^{8}$ Cuando Alvarado aceptó la imposibilidad de seguir adelante en la política de Yucatán, propuso a Carranza que el general Ignacio Enríquez o el mismo De la Huerta fueran enviados al estado como "moderadores" en la disputa acerca de quién llevaría las riendas durante el periodo de elecciones para gobernador, asunto crítico dados los ánimos exaltados entre los socialistas y los liberales yucatecos. ${ }^{9}$ Carranza decidió que en octubre de 1917 , De la Huerta viajara a Yucatán a solucionar la crisis. Después de un largo viaje que lo llevó a Nueva Orleáns y luego a Mérida, vuelta realizada para evitar el paso por el territorio oaxaqueño del rebelde general Higinio Aguilar, el enviado presidencial encontró al "hombre de Yucatán" en el doctor Álvaro Torre Díaz, secretario de gobierno y persona de las mayores confianzas del general Alvarado, quien continuaría como gobernador interino hasta febrero de 1918, cuando entregó el poder a Carlos Castro Morales. ${ }^{10}$ Complacido por la misión cumplida de Adolfo de la Huerta en Yucatán, Carranza lo llamó a su regreso a la capital del país y le confirió de inmediato una nueva tarea. Inquieto por la situación política de México en esos momentos, dio al sonorense la tarea de hacer una amplia investigación sobre el terreno y de plantear las

\footnotetext{
${ }^{8}$ Gilbert M. Joseph, Revolución desde afuera: Yucatán, México y los Estados Unidos, 1880-1924, México, FCE, 1992, p. 142-143. Francisco José Paoli, Yucatán y los origenes del nuevo Estado mexicano: gobierno del general Salvador Alvarado, 1915-1918, México, ERA, 1984, p. 136-137.

9 "Adolfo de la Huerta [...] no queriendo hacer a los yucatecos el deshonor de gobernar aquella entidad federativa sin ser hijo de Yucatán, le suplicó [a Carranza] le concediera la facultad de escoger algún yucateco que garantizara la imparcialidad de las elecciones...", Resumen biográfico..., op. cit., p. 3.

10 "Carranza: friend and foe!", manuscrito sin autor, en AFDH, p. 7-8. La versión del coronel Mena Brito, candidato a gobernador por el Partido Liberal Yucateco (PLY) fue muy otra. Relata que se acercó al presidente Carranza manifestándole que si no intervenía en el embrollo yucateco para frenar al "nefasto alvaradismo" y tener las garantías apropiadas, se retiraría de la campaña. Carranza resolvió enviar a De la Huerta para que le informase acerca de la situación política en Yucatán y de los alegados abusos de Salvador Alvarado. De la Huerta llegó a Mérida a principios de octubre de 1917, y presenció desde el balcón del "Gran Hotel", donde se hospedaba, una manifestación menista de "treinta mil personas de todas las clases sociales". De la Huerta regresó a la ciudad de México, con un informe que "debía" ser desfavorable a Alvarado, pero, para sorpresa de Mena Brito, pronto llegaría a Mérida el general Alvarado, a "controlar" las elecciones para poderes locales. Años después, don Adolfo le comentó a Mena Brito que el informe había sido favorable a Alvarado, "porque se comprometió a que no se volvería a cometer ninguna fechoría en ese Estado", Bernardino Mena Brito, Reestructuración histórica de Yucatán: influencia negativa de los políticos campechanos, en los destinos de México y de Yucatán, de 1914 a 1969, México, Editores Mexicanos Unidos, 1969, t. III, p. 237-239.
} 
recomendaciones que juzgase pertinentes. Lo instruyó para que realizara un viaje por algunas regiones del país-presumiblemente el centro-y hablara con los líderes políticos de todos los partidos. Durante 15 días, De la Huerta escuchó querellas, afrentas, quejas, lamentos y sugerencias. Regresó a la ciudad de México con un informe en la mano, en el que estaban apuntados cincuenta y un temas mayores que requerían la intervención del presidente. Ellos traían sus propias sugerencias, y casi todas fueron puestas en práctica por el ejecutivo, incluyendo el cambio de gobernadores, generales, consejeros financieros y otros. ${ }^{11}$

La guerra europea, para ese entonces, amenazaba con presentar dificultades en la política internacional de México por las sospechas norteamericanas de que la germanofilia de Carranza se materializaría en alguna alianza con Alemania. Los alegados juegos diplomáticos del presidente mexicano con Berlín y Tokio, traducidos en la controvertida "neutralidad benévola de México", los esfuerzos de Berlín por atraérselo con miras a la inminente guerra con los Estados Unidos, la oposición carrancista a las políticas mexicanas de Wilson, y el célebre telegrama Zimmermann, entre otros, crearon en los altos círculos de Washington la sospecha de que Carranza les acabaría disparando desde la trinchera contraria. Aun cuando Carranza y sus principales asesores -Cándido Aguilar y Manuel Aguirre Berlanga, entre otros-veían en Alemania un contrapeso efectivo frente a los Estados Unidos, el asunto fue manejado con pies de plomo pese a los efectos explosivos del affaire Zimmermann. Sin embargo, el presidente mexicano se mantuvo apartado de las tentaciones de una alianza militar y económica con Alemania en contra de la potencia del norte, ${ }^{12}$ aunque las protestas de neutralidad de Carranza no fueron suficientes para cambiar el juicio de los estadounidenses hacia su gobierno. Carranza era considerado definitivamente proalemán en el país del norte, y era necesario convencer a los funcionarios de su gobierno que era ajeno a las maquinaciones germanas. Periódicos como The New York Times y las compañías petroleras alentaban la idea de que México estaba en complicidad con los alemanes a fin de privar de combustible a Estados Unidos y Gran Bretaña en plena guerra. Frente a los temores deri-

\footnotetext{
"Ibid., p. 8-9; Resumen biográfico..., op. cit., p. 3.

${ }^{12} \mathrm{El}$ mejor trabajo publicado hasta ahora sobre el tema es el de Friedrich Katz, La guerra secreta en México: la Revolución mexicana y la tormenta de la primera guerra mundial, 2 v., México, ERA, 1982, v. 2, en los capítulos 9 y 10, p. 11-154. Sobre el telegrama Zimmermann y sus consecuencias, véase también el de Barbara W. Tuchman, El Telegrama Zimmermann, México, Grijalbo, 1960. Douglas W. Richmond, La lucha nacionalista de Venustiano Carranza, 1893. 1920, México, FCE, 1986, p. 278-282.
} 
vados de las simpatías mexicanas hacia Alemania, el secretario de Estado planteó al presidente Wilson la conveniencia de ocupar puntos estratégicos de la geografía mexicana, tales como la zona petrolera y el ferrocarril de Tehuantepec, amén de proteger la frontera de los Estados Unidos con su vecino del sur. ${ }^{13}$ En diciembre de 1917, Carranza envió a De la Huerta a los Estados Unidos con la encomienda de convencer a los círculos económicos y periodísticos de este país acerca de la falsedad de los rumores en el sentido de que México acabaría por ponerse del lado alemán. En un principio, De la Huerta declinó participar en esta tarea, argumentando su ignorancia del inglés y la mayor capacidad de acción del embajador mexicano en Washington, el célebre Ignacio Bonillas. "Sin más remedio que obedecer", durante días Carranza le reveló sus planes a fin de darle elementos para poder realizar con éxito su misión en los Estados Unidos. A punto de abandonar la ciudad de México hacia el extranjero, Carranza le "encontró" la cobertura oficial necesaria. Cándido Aguilar, secretario de Relaciones Exteriores, hizo llegar al presidente un telegrama procedente de la embajada en Washington, en el que se pedía la remoción del cónsul general en Nueva York, el señor Juan T. Burns, sosteniendo que era abiertamente proalemán en su actitud y opiniones. El gobierno de los Estados Unidos, sabedor de la inclinación de este cristianísimo caballero, pero deseando evitar un incidente diplomático con su expulsión, había dado señales sobre la necesidad de que Burns fuera retirado. El gobierno de México nombró de inmediato a De la Huerta en su lugar. En aquellas pláticas confidenciales, Carranza hizo una revelación que apoyaba la potencialmente peligrosa germanofilia del presidente:

personal e íntimamente, en mis sentimientos estoy en favor de Alemania y las Potencias Centrales en esta guerra mundial [...] Pero yo soy mexicano antes que todo y me doy cuenta que la neutralidad es lo mejor para México, por lo que sin importar las insinuaciones que me han llegado, he sumergido mis sentimientos personales y México debe ser honestamente neutral. ${ }^{14}$

El flamante cónsul De la Huerta coincidió y unió esfuerzos con Bonillas, un simpatizante decidido de la causa aliada. ${ }^{15} \mathrm{~A}$ través de

${ }^{13}$ Lorenzo Meyer, México y Estados Unidos en el conflicto petrolero (1917-1942), México, El Colegio de México, p. 89.

14 "Carranza, friend and foe!", op. cit., p. 10.

${ }^{15}$ Así entendía De la Huerta la importancia del consulado en Nueva York: "El Consulado General de Nueva York es de trascendentalísima importancia, pues es en aquella plaza en donde se incuban muchos de los problemas políticos por la fuerza de las corrientes capitalis- 
contactos privados y la prensa, ambos anunciaron la neutralidad mexicana y, en general, mejoraron la imagen del presidente Carranza en los círculos políticos y financieros, y ante la opinión pública de este país. El argumento principal del Departamento de Estado era la decisión con que defendía la causa alemana el periódico $E l$ Demócrata, por la inocultable simpatía de Rafael Martínez, "Rip-Rip", su director. De la Huerta replicó, en defensa de la neutralidad mexicana, que la misma libertad tenía la campaña anglófila de El Universal, de Félix Palavicini, el periodista más destacado de México en su momento. ${ }^{16}$ Más aún: De la Huerta agregó que tanto El Demócrata como El Universal contaban con el apoyo financiero del gobierno, para estimular el debate político, porque de no existir esos dineros, simplemente no habría publicaciones de este tipo en México. ${ }^{17}$ Por lo demás, De la Huerta puso en claro los alcances y limitaciones de la ayuda mexicana a los Estados Unidos en el esfuerzo de guerra, en materias primas y otros, incluyendo el petróleo, como prueba de la buena voluntad mexicana. ${ }^{18}$ En Nueva York, De la Huerta tuvo contactos intensos con el Departamento de Estado, periodistas y financieros con intereses en México, que sin duda contribuyeron al cambio de posturas oficiales y privadas hacia Carranza. ${ }^{19}$ De manera definitiva, el armisticio de noviembre de 1918 dejó atrás las preocupaciones sobre la germanofilia carrancista en ese país.

Mientras De la Huerta se encontraba en Nueva York, fue nominado candidato a gobernador, en las elecciones de abril de 1919, por el Partido Revolucionario Sonorense, en contienda con los generales Ignacio L. Pesqueira (el candidato del centro), Miguel Samaniego y Conrado Gaxiola. Este último era hermano de Ignacio Gaxiola, socio de la firma Álvaro Obregón \& Cía., quien fue apoyado de diversos modos por el general durante su campaña. ${ }^{20}$ Habiendo acepta-

tas en aquel centro, y es también la fuente en donde hay que conseguir datos de índole comercial y financiera que deben hacerse llegar a la superioridad para aprovechamiento de la Secretaría de Hacienda y de la Economía Nacional. La orientación de la prensa en aquel centro es importantísima y la documentación que hay que llevar a los hombres de negocios de aquella metrópoli ha de ser muy amplia y hábil, por lo que ese representante debe ser personalidad de fuerza política, de extensa preparación mercantil y de reconocida integridad en su vida pública y privada, y ha de ser un colaborador eficaz de nuestra embajada en Washington". "Consulados Generales", informe sin fecha, redactado por Adolfo de la Huerta como visitador general de consulados, en $A D L H$.

${ }^{16}$ Rivera, op. cit., p. 498.

${ }_{17}^{17}$ Entrevista del autor con Adolfo de la Huerta Jr., 25 de enero de 1981.

18 Roberto Guzmán Esparza, Memorias de don Adolfo de la Huerta, según su propio dictado, México, Ediciones Guzmán, 1958, p. 103.

${ }^{19}$ Véase, a manera de ejemplo, The New York Times de la segunda semana de septiembre de 1918.

${ }^{20}$ Guzmán Esparza, op. cit., p. 108. 
do tal postulación, De la Huerta renunció a su puesto de cónsul y regresó a la ciudad de México a mediados de diciembre, a presentar cuentas a Venustiano Carranza.

El presidente, sin embargo, tenía otros planes para Sonora. Ya encaminado en tomar medidas preventivas para debilitar a Obregón y a sus aliados sonorenses, hizo su primer intento por dividirlos. Ofreció a De la Huerta la Secretaría de Gobernación, argumentando que el que estaba en el puesto era proalemán, y que deseaba confirmar a los Estados Unidos sus posturas favorables a los aliados. Nadie mejor que De la Huerta en su lugar, dado su exitoso trabajo en Nueva York. Pero éste se mantuvo en su decisión de regresar a Sonora, por lo que Carranza trató en vano de detener su partida hacia Hermosillo, asignándole tareas fútiles para cumplir en la capital de la república durante todo el mes de enero de 1919. De la Huerta, una vez convencido de la táctica de Carranza de enfrentar a los líderes sonorenses frente a su sucesión en el poder ejecutivo, sin avisarle al presidente tomó el tren para su tierra, a donde llegó sin novedad el 5 de febrero. "Esto nunca me lo perdonaría", afirmó don Adolfo seguramente con razón. ${ }^{21}$ Mientras tanto, el general Álvaro Obregón, secretario de Guerra, renunciaba a su puesto y anunciaba su retiro político activo en Sonora.

De la Huerta resultó triunfante en la contienda por la gubernatura de abril de 1919 por amplio margen, con 21 mil votos, frente a los 11 mil de Pesqueira y los nueve mil de Gaxiola. ${ }^{22}$ Ello, a pesar de que el presidente Carranza había proporcionado considerables recursos pecuniarios en favor de su candidato, el general Ignacio L. Pesqueira, y que los funcionarios federales y tropas acantonadas en su estado natal tenían instrucciones de apoyar al hombre del centro. La toma de la gubernatura sería hasta el 1 de septiembre siguiente, para sustituir al gobernador en funciones, Plutarco Elías Calles. En el ínterin, Carranza ordenó a De la Huerta presentarse en la ciudad de México, instrucción que acató de inmediato. Incidentalmente, mantenía el puesto de senador para el que había sido elegido mientras se encontraba en los Estados Unidos. Desde el Senado, De la Huerta observaba de cerca los acontecimientos en la capital, promovía sus contactos en diferentes esferas y tomaba el pulso político al país.

La sucesión presidencial de 1920 era el mayor asunto político durante esta época. Desde noviembre de 1918, habían empezado a sonar con fuerza los nombres de Álvaro Obregón y Pablo González

21 "Carranza, friend and foe!", op. cit., p. 11

${ }^{22}$ Rivera, op. cit., p. 499. 
como aspirantes a la silla de los presidentes. A principios del año siguiente, era claro que Obregón se preparaba para emprender la carrera a la presidencia, en el entendido de que Carranza estaría de acuerdo en que fuera su sucesor. ${ }^{23} \mathrm{El}$ coahuilense, por su parte, si bien tenía clara su decisión de no reelegirse a pesar de que sus intimos le instaban a hacerlo, ${ }^{24}$ para su mala fortuna resolvió impedir la llegada de Álvaro Obregón a cualquier precio, quebrantando con ello una promesa empeñada de dejar el campo libre al sonorense. A un interlocutor le confesó que Obregón como presidente sería caótico, porque carecía de un plan de gobierno, no entendía los problemas nacionales ni tenía las virtudes necesarias para gobernar. ${ }^{25}$ Levantando el pendón del llamado "civilismo", una orientación que lucía acorde con su propia conducta personal y política (él no era el "general" Carranza), se decidió callada, primero, y abiertamente después, a buscar a un candidato de prestigio, ajeno al ejército y capaz de hacer contrapeso a Obregón. El prurito carrancista, tan conocido, fue impedir que México quedase bajo el imperio del militarismo, pero algunos motivos menos nobles pudieron haber estado en la mente del Primer Jefe para haber tomado decisión tan temeraria. José Fuentes Mares los explicó en tono sarcástico:

Cargado de virtudes personales, el famoso Varón de Cuatro Ciénegas era un resentido que toleraba en los demás todo menos el éxito, y Obregón era un éxito [...] Pero como él no ganaba batallas, sino que se las ganaban, en Celaya también se le clavó otra espina, la de Obregón, la misma que ahora le escocía hasta los tuétanos. ${ }^{26}$

Adolfo de la Huerta se dirigió al Palacio Nacional, a saludar a Carranza, quien le protestó, con sonrisas y explicaciones no solicitadas, una amistad que se derrumbaba. Negó haber apoyado al general Ignacio L. Pesqueira y en cambio le manifestó que "aunque no lo supiera", tal apoyo había sido en realidad a favor del bando delahuertista. El remate, si no sorpresivo, fue de una ingenuidad inverosímil, salido de alguien que era ducho en artes maquiavélicas. "Mi amigo, usted debería contender por la Presidencia de México [...]

\footnotetext{
${ }^{23}$ Hall, op. cit., p. 192.

24 "Juntas militares", Archivo General de la Nación, ramo Presidentes Obregón.Calles (AGN/ $o c)$, 101-R-2-H. 192.

${ }^{25}$ Bernardo Mena Brito, Ocho diálogos con Carranza, p. 784-785, citado por Hall, op. cit., p.

${ }^{26}$ José Fuentes Mares, "Carranza y la técnica electoral", en Diorama de la Cultura, 1 de noviembre de 1970 . D. 8 .
} 
Necesitamos a un civil, no a un guerrero como Obregón." La maniobra de Carranza era una pedrada que buscaba matar dos pájaros. Con De la Huerta en carrera hacia la Presidencia, el voto sonorense se dividiría para asegurar la derrota de Obregón. Además, don Adolfo tendría que renunciar a su puesto de gobernador de Sonora y dejar libre el camino al carrancista Pesqueira, al mando del estado en días de elecciones. La negativa fue contundente, fincada en el compromiso de mantener las mutuas promesas hechas en el pasado: Carranza no sería estorbado por Obregón, a quien le sobraban ganas y recursos para llegar a la presidencia, a cambio de que en el siguiente periodo, el de Huatabampo no tuviera la oposición del presidente para sucederlo. ${ }^{27}$

El origen de esa promesa de Carranza a De la Huerta y Obregón se remontaba a los tiempos de la Convención de Querétaro de 19161917. Desde las sesiones preliminares se perfilaron dos grupos fundamentales y antagónicos: los llamados "renovadores", designados por Carranza para imponer su moderado proyecto, y los "jacobinos" o "radicales de Obregón", con la consigna de imponer la presencia del reformismo social. Entre ellos osciló un grupo de independientes. ${ }^{28}$ Esta división reflejaba las principales posturas encontradas en el campo constitucionalista, en la que acabaron predominando los radicales. Este panorama favorecía a Obregón, en detrimento de la fortuna política de su antiguo jefe. Además, aquél había acumulado poder sobre el ejército, la institución de mayor fuerza y prestigio desde el fin del Porfiriato, y ganado bonos al identificarse con grupos y movimientos de expectativas crecientes durante la Revolución. Obregón estaba consciente de que la relación de fuerzas al interior del constitucionalismo le era favorable por amplio margen, porque nadie más que él se había beneficiado de los errores de Carranza, sobre todo en sus tratos con los grupos emergentes. ${ }^{29}$

\footnotetext{
${ }^{27}$ National Archives of the United States (NAW), Border Report, June 21, 1919, Papers relating to the Internal Affairs of Mexico, 812.00/22752; "Carranza, friend and foe!", op. cit., p. 13; Guzmán Esparza, op. cit., p. 138-139. Ing. Arturo de la Huerta, entrevista en Guaymas, 23 de octubre de 1994. M/DLH, respuesta a la pregunta 75. Miguel Alessio Robles habla de un acuerdo tácito entre Carranza, Obregón y Pablo González. Consistía en que estos militares no estorbarían la candidatura a la Presidencia del Primer Jefe en las elecciones de 1917, y tres años después, en las de 1920, figurarían como candidatos Obregón y Pablo González. Miguel Alessio Robles, A medio camino, México, Editorial Stylo, 1949, p. 25-26.

${ }^{28}$ Ward M. Morton, "The Mexican Constitutional Congress of 1916-1917", en Southwestern Science Quarterly, 33 (June, 1952), p. 11-15; Aarón Sáenz, “Alvaro Obregón”, Historia mexicana. Centro de Estudios Históricos de El Colegio de México, núm. 10 (octubre-diciembre de 1960), p. 309. Narciso Bassols Batalla, El pensamiento político de Álvaro Obregón, México, El Caballito, 1976, p. 27.

${ }^{29}$ Arnaldo Córdova, La ideología de la Revolución mexicana: la ideologia del nuevo régimen, México, Era, 1981, p. 218. Richmond, op. cit., p. 298-299.
} 
El Primer Jefe veía en Obregón a un enemigo cada vez más peligroso, con la capacidad y el arrojo suficientes para anularlo, si las circunstancias se lo permitían. Carranza recurrió entonces a De la Huerta para que le propusiera un arreglo decoroso a Obregón y sus partidarios. Con el argumento que bien podía esgrimir su rival, el Primer Jefe "deseaba disfrutar los frutos de sus penalidades sufridas durante la lucha armada", ocupando la presidencia durante un periodo "para probarse". Cenfiando en De la Huerta, le pidió que convenciera a los "radicales" pro-obregonistas a alinearse a su favor. Ellos acabaron entrevistándose "uno por uno" con el Primer Jefe, a quien protestaron su apoyo y lealtad para que ocupara la presidencia, "al menos por un periodo". Acudiendo al "mayor conocimiento y poder sobre Obregón", Carranza pidió al de Guaymas convencer a Obregón que reconociera sus derechos precedentes sobre la silla. De la Huerta accedió con reservas a lo que se le pedía, y logró cambiar su determinación de disputar el puesto a su jefe. Lo hizo con la condición de que Carranza no se opusiera a sus aspiraciones presidenciales en 1920. Don Venustiano prometió que así lo haría. ${ }^{30}$

En enero de 1919, Carranza dio la primera señal, a través de un manifiesto muy difundido, de que Obregón no sería su candidato. Hizo ver que faltaba todavía mucho para la sucesión, y que la efervescencia política podría causar problemas. En lenguaje equívoco, dijo que tal anticipación "determinaría que los ciudadanos, especialmente los hombres con cierto prestigio político en sus respectivas regiones, confiaran prematuramente en ciertas promesas antes de que hubieran tenido tiempo de reflexionar suficientemente". ${ }^{31}$ Llamó a todos los elementos que habían militado en el constitucionalismo a unirse alrededor del gobierno. El enemigo de la Constitución de 1917, afirmó don Venustiano, no está vencido; en consecuencia, no es saludable ni conveniente una división de los elementos revolucionarios, que sería causada por la adquisición prematura de compromisos políticos con los posibles candidatos presidenciales. Pero fue una carta pública de don Luis Cabrera la que enturbió más las aguas. Señaló, entre otras cosas, que Carranza tenía compromisos amistosos con los militares que lo acompañaron en la lucha contra Huerta, y que tales compromisos constituían un "lastre político" que le impedía resolver el problema de la sucesión con

\footnotetext{
30 "Carranza, friend and foe!", op. cit., p. 1-3. Esta versión se encuentra también en William Weber Johnson, Heroic Mexico: the Violent Emergence of a Modern Nation, Garden City, Doubleday \& Co. Inc., 1968, p. 323.

${ }^{31}$ Excélsior, 15 de enero de 1919, citado por Hall, op. cit., p. 193-194. Bassols, op. cit., p. 28.
} 
libertad. Aunque, sin duda, Obregón y Pablo González "tenían... lastres políticos que les impedían actuar de una manera desinteresada”. El general Obregón, usando el seudónimo de Clemente Reynoso, respondió con una fuerte crítica a Cabrera, afirmando que la situación se caracterizaba por grupos de parásitos que giraban en torno de los caudillos en espera de favores. Acusó a Carranza de provocar los movimientos políticos y saber hacia dónde se orientaban, a través de sus declaraciones al periodista Rafael Martínez, "Rip-Rip”. En desvaída metáfora, Obregón manifestó que "el oleaje" de la opinión pública empezó a favorecer naves poco apropiadas para transbordar a ellas el "lastre político" del presidente, y el movimiento fue condenado por él como prematuro e inconveniente, por medio de su manifiesto. ${ }^{32}$

Carranza y Obregón rompieron lanzas en el verano de 1919. Éste, desde su retiro voluntario, no recibía ninguna señal de que el presidente estuviera dispuesto a cumplir con su parte del trato. Decidió entonces pasar a la ofensiva. El general Francisco Serrano, uno de los más conspicuos obregonistas y presidente del Partido Revolucionario Sonorense, lanzó la candidatura de don Álvaro. Éste, sin tardanza, dio a conocer su célebre Manifiesto de Nogales -o "de la resaca"- del 1 de junio, en donde declaraba que en los últimos meses "había sentido algo así como la resaca que llega a las playas cuando los mares se agitan en su centro". Este manifiesto fue una llamada de atención a Carranza ante sus señales de incumplir su promesa de abrirle el camino a la presidencia. Con oceánico reproche, Obregón de plano acusó al régimen de su antiguo jefe como inmoral y aseguró que el país vivía en una intranquilidad constante. ${ }^{33}$ Carranza, en quien su templanza corría al parejo de su tozudez, en esta ocasión perdió los estribos y aprovechó las circunstancias para retirarle el imaginario apoyo para que fuera su sucesor en la silla presidencial, que nunca había existido ni siquiera en intención. ${ }^{34}$ Las adhesiones a la candidatura de Obregón fluyeron en cascada. Apenas en julio de 1919, el Partido Liberal Constitucionalista (PLC) lo declaró su candidato; en agosto firmó un convenio de apoyo con la Confederación Obrera Mexicana (CROM) -que dio origen al Par-

\footnotetext{
${ }^{32}$ Bassols, op. cit.; Hall, op. cit., p. 195, citando a Luis Cabrera, carta a un amigo no mencionado, 14 de marzo de 1919, en Luis Ruvalcaba (comp.), Campaña política del C. Alvaro Obregón, candidato a la Presidencia de la República, 5 v., México, 1920-1924, v. I, p. 22-31.

${ }^{33}$ Fuentes Mares, op. cit., p. 9. El doctor Álvaro Matute comenta y hace una reconstrucción de este manifiesto en "La carrera del caudillo", Historia de la Revolución mexicana, 1917.1924, v. 8, México, El Colegio de México, 1980, p. 33-41.

${ }^{34}$ Alessio Robles. ob. cit.. D. 32-33.
} 
tido Laborista- y en septiembre el Partido Cooperatista le externó su respaldo. Ante Carranza, se hizo evidente de inmediato lo que debía sospecharse: la demoledora capacidad de convocatoria política de Obregón que sería dirigida contra el grupo en el poder.

Decidido a evitar el destino del que no escaparía, Carranza emprendió su lucha contra Obregón y apoyó con todas sus fuerzas a su débil candidato Ignacio Bonillas, quien regresó a México apenas en marzo de 1920, cuando Obregón y González dominaban el panorama electoral del país. ${ }^{35}$ Los bonillistas, con la bendición oficial, habían organizado el Partido Nacional Democrático (PDN), el cual lanzó a su candidato, en ausencia, el 23 de noviembre de 1919, vendiéndolo al electorado como el candidato que impediría el choque militar entre los dos rivales por la presidencia, Álvaro Obregón y Pablo González. ${ }^{36}$ González, aunque medianamente disciplinado al carrancismo se negó a respaldar a Bonillas y lanzó su propia candidatura el 13 de enero de 1920, apoyado por el Partido Progresista (PP) ${ }^{37}$ Esta iniciativa de González disgustó sobremanera a Carranza, quien le pidió que la retirara, porque su triunfo significaría la guerra civil. Esgrimiendo su tesis de la lucha entre las dos corrientes militaristas, le manifestó que un posible triunfo suyo resultaría en que "Obregón y su gente se levantaran en armas y viceversa, pudiendo ocasionarse con esto graves transtornos". ${ }^{38}$

El general Pablo González no solamente mantuvo su negativa a apoyar la candidatura civilista, sino incluso se entrevistó con su candidato Bonillas. Advirtiéndole acerca de los "resultados funestos a que nos conduciría la imposición", le propuso que ambos renunciaran a sus respectivas candidaturas. Bonillas habría estado de acuerdo con esta propuesta, que se daría a conocer a través de un manifiesto conjunto que explicara las razones y los caminos a seguir en el futuro. Pero Carranza se mantuvo en su posición de apoyar la candidatura civil y así se lo hizo saber a Pablo González. Aquí tuvo lugar el rompimiento entre los dos personajes ${ }^{39}$ Los partidarios de Obregón, por su parte, buscaron acercarse al gonzalismo para fulminar a Bonillas. Con esta intención se dio el "encuentro accidental" entre González y Obregón el 11 de abril en el restaurante del Lago de

\footnotetext{
${ }^{35}$ Richmond, op. cit., p. 312-313. El Universal, 25 de febrero de 1920.

${ }^{36}$ El Demócrata, 24 de noviembre de 1919.

${ }^{37}$ Sonia Quiroz, "La rebelión de Agua Prieta, 1919-1920", en Nuestro México, 10, Universidad Nacional Autónoma de México, 1984, p. 3. El Demócrata, 17 de noviembre de 1919.

38 "General Pablo González", en Recopilación de documentos y de algunas publicaciones de importancia, Partido de Reconstrucción Nacional, Sección de Prensa y Publicaciones, abril de 1923, p. 276.

${ }^{39}$ Ibid., p. 279.
} 
Chapultepec. Según González, Obregón aludió al peligro "mediato" en que se encontraban, al imponerse el candidato oficial de la presidencia, y al "inmediato" de ser aprehendidos para no estorbar los planes del gobierno. Le propuso oponerse a Carranza por la fuerza, que su interlocutor rechazó. El abrazo del gonzalismo y el obregonismo, juzgado funesto a la postre por Pablo González, tuvo el efecto de reforzar las posiciones obregonistas en detrimento de Carranza, quien a los ojos de todos estaba cada vez más aislado y debilitado. ${ }^{40}$

Álvaro Obregón parecía tener las soluciones a los principales problemas que asolaban a México. Se presentaba con la imagen del más limpio y democrático: criticaba la inocultable corrupción carrancista, era el "defensor del voto popular" y enemigo de las imposiciones oficiales, $y$ hasta adalid del civilismo, y para mejor prueba estaba su controvertida renuncia a su grado militar. ${ }^{41}$ Ante la popularidad arrasadora de Obregón y la candidatura independiente de González, en quien el gobierno ya no podía confiar, el presidente decidió apretar el paso. A principios de enero de 1920, el presidente dio a conocer una proclama en la que pedía a los militares presidenciables que renunciaran. Los partidarios de Obregón, por su parte, protestaron ante lo que juzgaron una intromisión indebida de Carranza en las elecciones. ${ }^{42}$

El presidente, buscando reforzar la base de apoyo a su candidato Bonillas, convocó a un grupo de gobernadores encabezados por el de Guanajuato, general Federico Montes, a una reunión en la ciudad de México para discutir la forma de lograr una transmisión pacífica del poder. Del 6 al 9 de febrero de 1920, 17 invitados deliberaron y manifestaron inequívocamente su apoyo al candidato oficial. Entre los grandes ausentes estuvieron Adolfo de la Huerta, Enrique Estrada ( gobernador de Zacatecas), Carlos Green (Tabasco) y Pascual Ortiz Rubio (Michoacán), para quienes su obregonismo estaba plenamente definido. ${ }^{43}$

De la Huerta, "quien no obtuvo permiso de la legislatura para dejar Sonora", expresó que tal postura significaba la aprobación del candidato oficial por parte de los gobernadores. ${ }^{44} \mathrm{Al}$ final de la reunión, los gobernadores asistentes dieron a conocer un manifiesto, en el que se negaron las intenciones del gobierno de "conculcar

${ }^{40}$ Ibid., p. 282-283.

${ }^{41}$ Hall, op. cit., p. 202-203.

${ }^{42}$ El Monitor Republicano, 19 de enero de 1920; El Demócrata, 18 de enero de 1920.

${ }^{43}$ Matute, op. cit., p. 85. Excélsior, 6 de febrero de 1920.

${ }^{44}$ Quiroz, op. cit., p. 4. El Universal, 11 de febrero de 1920, NAW, Francis V. Dyer to Secretary of State, February 9, 1920, 812.00/233861. 
la libertad de sufragio" y declararon que las expresiones en este sentido eran "como un preliminar para hacer pública la intención de no acatar el voto del pueblo en el caso de que aquél les sea desfavorable". Es de destacar, sobre todo, el compromiso de apoyar al presidente de la República desde el día de la elección hasta el de la transmisión del poder. ${ }^{45}$ Adolfo de la Huerta, sin tardanza, señaló que el manifiesto buscaba persuadir a los estados a apoyar a Bonillas e intimidar a los votantes. ${ }^{46}$

Después de un breve interinato, De la Huerta recibió por enésima vez la gubernatura de Sonora, de manos del general Plutarco Elías Calles, el 1 de septiembre de 1919. Desde el principio de su mandato, el gobierno federal empezó a presionar con el objetivo de debilitarlo y, si era posible, de expulsarlo del poder. Ya desde meses atrás, cuando Obregón dio muestras ostensibles de querer ocupar la presidencia, Carranza había lanzado su primer ataque. Con ánimo provocador, el 11 de junio de 1919, Carranza decretó que el río Sonora era propiedad de la federación, "atendiendo a que tiene aguas permanentes, requisito que establece el artículo 27 de la Constitución Federal en vigor, para que las aguas de la corriente de que se trata tengan el carácter indicado". ${ }^{47}$ Aun cuando Calles no advirtió irregularidades en el asunto, o si las advirtió prefirió no dar ninguna respuesta, sí lo hizo De la Huerta, quien solicitó la reconsideración del acuerdo presidencial, con el argumento de que las aguas tanto del río Sonora como las del San Miguel Horcasitas eran de régimen torrencial y que eran motivo de ingresos fiscales para los municipios localizados en sus márgenes. ${ }^{48}$ Don Adolfo no se encontraba solo en lo que iba a ser una ríspida controversia con su antiguo jefe. Un clima de apoyo popular en Sonora había sido creado previamente por el periódico Orientación, de Clodoveo Valenzuela, y pronto llegaron los respaldos de los ayuntamientos de los municipios afectados por el decreto. ${ }^{49} \mathrm{El}$ diferendo continuó a pesar de las seguridades del secretario de Agricultura, Pastor Rouaix, a De la Huerta, de que aun cuando los ríos eran federales, sus aguas podían ser usufructuadas por los interesados en hacerlo. ${ }^{50}$

${ }^{45}$ El Universal, 11 de febrero de 1920.

${ }^{46}$ El Monitor Republicano, 3 de marzo de 1920.

${ }^{47}$ Pastor Rouaix a Calles, 11 de junio de 1920, en Clodoveo Valenzuela y Amado Chaverri, Sonora y Carranza: obra de la más amplia información periodística del ultimo movimiento libertario, respaldada por gran número de valiosos documentos hasta hoy desconocidos, que entregamos a la historia, México, Casa Editorial Renacimiento, 1925, p. 23. Rivera, op. cit., p. 507-508.

${ }^{48}$ De la Huerta a Carranza, 13 de enero de 1920, en Valenzuela y Chaverri, op. cit., p. 24-26.

${ }^{49}$ Ibid., p. 27-29.

${ }^{50}$ Pastor Rouaix a De la Huerta, 18 de febrero de 1920, en ibid., p. 38. 
El gobernador De la Huerta fue autorizado por el presidente Carranza para que, en nombre de la Federación, procurara la pacificación de la tribu yaqui y entrara personalmente en pláticas con los jefes de la misma, los generales Matus, Mori, Espinosa y Gómez. En las conferencias de paz participó también el entonces jefe de operaciones militares, general Juan José Ríos, en calidad de representante del gobierno federal. El resultado fue un histórico tratado que, por primera vez, reivindicó los derechos de los indígenas a cambio de la deposición de las armas, pero a última hora el presidente de la República se negó a aprobar los acuerdos de paz. ${ }^{51}$ Antes de concluir el año de 1919, el gobierno federal preparó una columna de dos mil hombres con destino a Guaymas, así como el envío de una cuadrilla de aeroplanos dirigida a la zona del Yaqui. ${ }^{52}$ De la Huerta no podía concebir que los yaquis pudieran levantarse en armas de nuevo, a menos que alguien quisiera causarle problemas. La intención de Carranza al desconocer su rendición, para luego enviar tropas contra ellos, era hacer que recayeran las culpas del rompimiento de la paz sobre el gobernador y generar así un serio conflicto interno, capaz de trastornar políticamente a los sonorenses. $\mathrm{Al}$ poco tiempo de haber tomado posesión, sin razón aparente, repentinamente estallaron manifestaciones antichinas en Sonora, donde De la Huerta vio "la mano maquiavélica de Carranza tras ellas" ${ }^{53}$ Grupos de agitadores amenazaron y maltrataron a los chinos de Sonora, ante la inacción del gobierno estatal, lo que causó que estos residentes y el gobierno chino protestaran ante Carranza ${ }^{54}$ Requerido por el presidente para explicar la situación, De la Huerta le telegrafió para manifestarle que "después de todo, tenemos un gran número de chinos en el estado, dedicados al comercio, que probablemente han causado un cierto resentimiento entre parte de nuestra gente. Éste es un elemento que debe ser considerado si queremos detener a los agitadores". La violenta respuesta de Carranza no dejó lugar a dudas: "Si usted no puede detener estas manifestaciones antichinas, yo lo haré." Así, a horas de la noche del día último del año de 1919, Carranza envió órdenes al general Juan Torres, comandante de las tropas federales, a arrestarle "porque no

\footnotetext{
${ }^{51}$ Edward H. Spicer, Los Yaquis: historia de una cultura, México, Instituto de Investigaciones Históricas, UNAM, 1994, p. 293-294; "El problema del Yaqui", editorial de Orientación, en Valenzuela y Chaverri, op. cit., p. 59-63. Valadés, op. cit., p. 30.

${ }^{52}$ El Demócrata, 7 de noviembre de 1919.

${ }^{53}$ Ibid., 14.

${ }^{54}$ Miembros de la colonia china de Cananea a Carranza, 22 de diciembre de 1919, Archivo Carranza (AC): citado Dor Richmond. ob. cit.. p. 314.
} 
había obedecido órdenes del gobierno federal". ${ }^{55}$ Alertado por un taquígrafo de la Jefatura de Operaciones Militares del estado de que la orden había llegado en la medianoche de Año Nuevo de 1920, De la Huerta esperó a la mañana al general Juan Torres. Al comunicarle las instrucciones que había recibido de la ciudad de México, el general le manifestó su postura de no obedecerlas, por su ilegalidad. Agregó que De la Huerta "era el gobernador legalmente elegido de Sonora y Carranza no tenía derecho a interferir" con él. Presto a contestar a Carranza con aspereza, diciendo que "el jefe de las Operaciones Militares no se prestaría por ningún motivo a violar la soberanía del Estado de Sonora", don Adolfo le ayudó a redactar una respuesta comedida al presidente Carranza, en la que el militar se daba por enterado de las órdenes, pero se negaba a acatarlas. ${ }^{56}$ Cuando don Venustiano leyó la comunicación del general Torres, le ordenó que se trasladara de inmediato a la ciudad de México, donde fue arrestado y juzgado por desobediencia. Pero antes de salir de Sonora, al despedirse de sus oficiales, les informó de su traslado y les pidió que velaran por que no fuera amenazada la soberanía del estado. Estos militares, sonorenses en su mayoría y al mando de alrededor de cuatro mil soldados, juraron lealtad y apoyo al gobernador De la Huerta. ${ }^{57}$

Enterado del cese del general Torres, el gobernador sonorense llamó al general Francisco R. Manzo, a quien puso en antecedentes de la inminencia de un choque armado con el centro. Previendo acertadamente el endurecimiento de las medidas de Carranza contra su gobierno, De la Huerta le pidió que organizase a la brevedad una milicia estatal, en colaboración con los presidentes municipales. El número de efectivos debería ascender a dos mil plazas. Pese a la gravedad de la situación, que parecía no dejar más camino que el estallido de la violencia, don Adolfo hizo intentos infructuosos por reconciliarse con Carranza. A principios de enero de 1920, escribió una carta al presidente, enviada a través de un mensajero, con las instrucciones de entregarla en persona a su destinatario y esperar la respuesta. Al cabo de dos semanas, el correo regresó con las manos vacías, solamente con la promesa de una respuesta en la primera oportunidad. Con esta actitud, quedaban definitivamente

55 "Proceda usted a la inmediata detención del señor Adolfo de la Huerta, quien deberá quedar bajo la vigilancia personal de usted, informando a esta Presidencia haber cumplido con la disposición", Valadés, op. cit., p. 31.

${ }^{56}$ De la Huerta, Resumen biográfico..., op. cit., p. 4. "Carranza, friend and foe!", op. cit., p. 1415.

${ }^{57}$ Ibid., p. 16; Valadés, op. cit., p. 32-33. 
suspendidas las relaciones entre De la Huerta y el gobierno federal. ${ }^{58}$ En tal comunicación, De la Huerta había intentado persuadir a Carranza de que cediera, "dejando que Obregón corriera sin su oposición a la presidencia y entonces las aguas estarían tranquilas". ${ }^{59}$ Pero Carranza no se dio por vencido y envió al general Juan José Ríos como nuevo jefe de Operaciones Militares en Sonora.

Plutarco Elías Calles, mientras tanto, se preparaba a dejar la ciudad de México. Carranza le había llamado después de dejar la gubernatura de Sonora a ocupar la Secretaría de Comercio e Industria, como parte de su estrategia para dividir a los sonorenses, como no tardaría Calles en darse cuenta. ${ }^{60}$ En enero de 1920 , justo cuando tenían lugar las dificultades entre De la Huerta y Carranza y mientras Obregón se encontraba de gira por el país, Calles renunció a su puesto ministerial para integrarse al Comité Director Obregonista ${ }^{61} \mathrm{El}$ puesto le fue particularmente útil, pues sirvió a sus fines de estrechar relaciones con el líder de la Confederación Obrera Revolucionaria de México (CROM), Luis N. Morones, así como con Felipe Carrillo Puerto, del Partido Socialista Yucateco, y otros importantes líderes obreros de la República, quienes también eran partidarios de Obregón. ${ }^{62}$ En lo que temporalmente sería el amplio plan de levantamiento obregonista, los obreros iban a ocupar también un papel importante. Los dirigentes mencionados predicaron la idea de una huelga general en todo el país, calculando que la fecha propicia para el estallido de ese movimiento fuera julio de aquel crucial año, cuando debían verificarse las elecciones que se calificarían de ilegales a causa de la intromisión oficial. ${ }^{63}$

La primera orden del general Ríos fue reanudar la campaña contra los indios yaquis, quienes se encontraban en paz. Dispuso que las tropas se trasladaran sigilosamente hacia la zona indígena, a fin de realizar movimientos envolventes y sorpresivos. El problema fue que los subordinados de Ríos se negaron a ejecutar sus órdenes. Para el general era claro que tras esta rebeldía estaba el gobernador De la Huerta y se dirigió furioso hacia el palacio de gobierno. Después de un episodio tormentoso, de agria y encendida discusión en la penumbra de los pasillos, ambos personajes midieron fuerza y

\footnotetext{
${ }^{58}$ Ibid., p. 32.

59 "Carranza, friend and foe!", op. cit., p. 17.

${ }^{60}$ Calles a De la Huerta, 26 de diciembre de 1919, en Valenzuela y Chaverri, op. cit., p. 75.

61 "Carranza, friend and foe!", op. cit., p. 17.

62 Fernando López Portillo, "Las memorias de D. Adolfo de la Huerta: algunas aclaraciones", en El Universal, 4 de febrero de 1958; Excélsior, 2 de febrero de 1920.

${ }^{63} M /$ AFDH. OD. cit., respuesta 75 .
} 
carácter. Pero al verse casi solo en Hermosillo, Ríos abandonó esta capital y se dirigió de inmediato a Guaymas, pensando que allí estaría más seguro. Desde aquí, tierra natal de don Adolfo, telegrafió a Carranza pidiéndole "ochocientos hombres nuevos de inmediato para controlar la situación". ${ }^{64}$

Mientras el general Ríos permanecía en Guaymas, Carranza envió al general Manuel M. Diéguez, veterano de las luchas mineras de Cananea, como último intento para que De la Huerta retirase su apoyo a Obregón. Diéguez llegó a Hermosillo acompañado de 200 dragones procedentes del centro, y se dirigió de inmediato al palacio de gobierno. De la Huerta persistió en su negativa a apoyar al candidato presidencial oficial..$^{65}$ En esta ocasión, De la Huerta protestó por la invasión federal a Sonora, a lo que Diéguez replicó que el movimiento de tropas "era rutinario", destinado a asegurar que los yaquis respetaran los compromisos de paz y de ninguna manera constituía una violación de la soberanía sonorense. Un asunto delicado que trataron fue el de la formación y desmovilización de las milicias estatales, organizadas a instancias del gobernador, en donde tampoco hubo acuerdos.

Para Diéguez quedaba claro el avance de los preparativos de los sonorenses para resistir al ejército federal y la imposibilidad de llevar a cabo su difícil tarea. ${ }^{66}$ Ignorante, sin embargo, de la situación desfavorable en que se encontraban los emisarios de Carranza en Sonora, Diéguez amenazó al gobernador con "ponerlo en orden" en caso de no acceder a sus demandas. En la noche del mismo día, seguramente ya informado por su lugarteniente Ríos de la delicada posición en que se encontraban los federales, estos leales al carrancismo cambiaron de actitud y prefirieron emprender la retirada de Sonora. Durante una pacífica entrevista con el gobernador De la Huerta, éste envió a través de ellos un último mensaje conciliador a Carranza. Al llegar a su casa, De la Huerta habría encontrado un telegrama de Calles, quien se encontraba enfermo en un hospital de Tucson, situación que lo había alejado del ambiente político durante 40 días: "acabo de escuchar acerca de tu situación peculiar con Carranza. Mañana me uniré a ti y estaré a tu lado. Plutarco Elías Calles". ${ }^{67}$ Al día siguiente, Calles llegó a Hermosillo. A petición de Adolfo de la Huerta, Diéguez y Calles se entrevista-

64 "Carranza, friend and foe!", op. cit., p. 18-19.

${ }_{65} \mathrm{M} / \mathrm{AFDH}$, op. cit., respuesta 75 .

${ }^{66}$ NAW, Border Report, March 15, 1920,812.00/22890, Orientación, Hermosillo, 12 de abril de 1920.

67 "Carranza, friend and foe!", op. cit., p. 19-20. 
ron y, en lugar de algún acuerdo, se acabaron de fijar los términos del conflicto entre Sonora y Carranza. El general Diéguez puso a continuación pies en polvorosa, y en cuanto estuvo a buena distancia de la frontera del estado de Sonora disparó telegramas a soldados, oficiales, funcionarios y políticos sonorenses con el texto siguiente: "Regresaré con veinte mil hombres, por lo que escojan su bando antes de que sea demasiado tarde. ${ }^{.68} \mathrm{~A}$ don Adolfo, por su parte, le comunicó que el gobierno del centro no aceptaba los motivos del gobierno de Sonora para pactar con los yaquis y que, en consecuencia, consideraba estos actos como un ataque al pacto federal. ${ }^{69}$

Carranza inmediatamente declaró que no reconocería más a De la Huerta como gobernador. Sin que mediara la declaración previa de poderes, nombró gobernador militar del estado al general Ignacio Pesqueira, y ordenó el movimiento de tropas a través de Chihuahua por el este y de Sinaloa por el sur. Ocho mil soldados federales se movilizaron desde Chihuahua, en camino al Cañón del Púlpito, paso entre este estado y Sonora. "Subyugando mi orgullo", apuntaría don Adolfo, "mandé telegrama tras telegrama a Carranza, urgiéndole a reconsiderar el envío de tropas a Sonora". En uno de ellos, refirió que la "prensa amarillista" de los Estados Unidos había propalado noticias sobre la imposición de un gobernador militar y que la presencia de Diéguez arruinaría la labor de pacificación del Yaqui. En su respuesta, Carranza sostuvo que el movimiento de fuerzas de Diéguez "obedecía más bien a necesidades de la campaña o a circunstancias que a juicio de este gobierno así lo requieren..." ${ }^{70} \mathrm{El}$ presidente no estaba dispuesto a modificar su postura ni un ápice, ni ante las súplicas desesperadas de De la Huerta: "Por favor detenga sus tropas. Llegaré a la ciudad de México y me rendiré. Me puede usted matar, pero si usted permite que esas tropas avancen sobre Sonora, defenderé la soberanía de mi estado hasta el final." A lo que Carranza respondería desafiante: "Yo no detendré a las tropas. Venga a México si quiere." Y Carranza, en un esfuerzo por "exhibir la cobardía" de De la Huerta, hizo que tales cables fuesen publicados por los periódicos de la ciudad de México.

El presidente Carranza actuó contra Sonora, apoyado en la presunción de que, en efecto, la rebelión largamente preparada por Obregón tendría a este estado como espacio central de una estrategia a la que se sumaba una red política constituida por líderes militares y civiles y alzados de diferentes partes de la república. El asun-

${ }^{68}$ Ibid., p. 21.

${ }^{69}$ Valadés, op. cit., p. 42.

${ }^{70}$ Carranza a De la Huerta, 2 de abril de 1920, en Valenzuela y Chaverri, op. cit., p. 155-156. 
to Cejudo y las cartas suscritas por el general Benjamín G. Hill y las enviadas por el rebelde zapatista Genovevo de la $\mathrm{O}$ evidenciaban a las claras los tratos de Obregón y sus agentes con los anticarrancistas levantados. El conjunto de acciones militares preparadas contra Sonora obedecían, entonces, al propósito de anticiparse con los medios disponibles y "de dar garantías a las personas y grupos que no simpatizaban allí con la candidatura del C. Obregón", según dijo el presidente a los generales Jacinto B. Treviño, Francisco J. Mújica y Esteban Baca Calderón, entre otros. ${ }^{71}$ Esta presión que Carranza ejerció contra Sonora derivó en el rompimiento precipitado de hostilidades entre el centro y este estado del norte y, en consecuencia, su dramática caída.

Los telegramas de abril de 1920 intercambiados entre Carranza y De la Huerta, para el segundo fueron un amplio sumario de las afrentas que el presidente había llevado a cabo en contra de Sonora. Junto a los asuntos conocidos, apareció una miscelánea de agravios, objeto de fuertes protestas de los sonorenses. A fin de restar fuerzas a la rebelión que se veía inminente, Carranza tomó severas disposiciones. Los fondos de las aduanas fronterizas fueron trasladados a bancos de Arizona. Se dispuso la suspensión de pagos a los soldados federales acantonados en Sonora. El gobierno federal dio apenas la décima parte de estampillas para impuesto del timbre, por un valor de 17 mil pesos. Carranza envió infantes de marina de Mazatlán a Guaymas con instrucciones de duplicar sus efectivos. Se habían cortado los fondos para los cuerpos rurales en la campaña del Yaqui. La Secretaría de Hacienda había permitido la exportación de toda clase de ganado, a fin de desabastecer a los habitantes de Sonora. Carranza intentaba atraerse a los enemigos del gobierno, los maytorenistas. La agresiva campaña editorial de El Demócra$t a$ a favor de las medidas contra el gobierno de Sonora era notable. ${ }^{72}$ Carranza rechazó las acusaciones y señaló a De la Huerta que podría acudir a la Suprema Corte de Justicia, a la que el artículo 103 constitucional permitía fungir como árbitro en los casos en que se hubieran violado los derechos de los Estados. ${ }^{73}$

Sonora se puso en pie de guerra. Su gobierno declaró públicamente la suspensión de relaciones con el gobierno central "hasta

\footnotetext{
${ }^{71}$ También les manifestó "que era pública la presión que ese grupo imponía en aquella entidad federativa y que lo que se deseaba era estar preparados para arrojar el guante en un momento dado, motivo por el que el gobierno del centro se había anticipado en cumplimiento de su deber". Jacinto B. Treviño, Memorias, México, Editorial Orión, 1961, p. 152.

${ }^{72}$ De la Huerta a Carranza, 4 de abril de 1920, en Valenzuela y Chaverri, op. cit., p. 159-160.

${ }^{73}$ Archivo de la Secretaría de Relaciones Exteriores de México (AREM). Carranza a De la Huerta, 9 de abril de 1920, LE 866-125-127.
} 
que las causas de tal determinación hayan cesado de existir". ${ }^{74} \mathrm{El}$ Congreso del Estado, en apoyo al ejecutivo, promulgó el 10 de abril la ley número 30 , que concedía facultades extraordinarias en los ramos de Hacienda y Guerra al ejecutivo, a fin de preparar la defensa. ${ }^{75}$ Por otro lado, don Adolfo convocó a los jefes militares a una junta, el 12 del mismo mes, para enterarlos de la tensa situación, resultado de la determinación de don Venustiano de atacar la soberanía del estado. En ese momento dispuso el cese del general Juan José Ríos como jefe de operaciones en Sonora, y el nombramiento del general Plutarco Elías Calles como jefe de la División del Cuerpo del Ejército del Noroeste, quien se había puesto bajo las órdenes del gobernador de Sonora desde el 9 de abril. ${ }^{76}$ Los preparativos de guerra partieron de la organización de las fuerzas federales disidentes, los voluntarios y los yaquis bajo el mando de Mori. ${ }^{77} \mathrm{El} \mathrm{Fe}$ rrocarril Sud-Pacífico fue incautado por las autoridades de Sonora a fin de adelantarse a una posible intervención de las líneas por parte del gobierno de la República. A Salvador Alvarado, quien por el momento se encontraba en Nueva York, le fue ordenado trasladarse a Washington con el propósito de conseguir créditos y allegarse apoyos en la capital norteamericana ${ }^{78} \mathrm{De}$ la Huerta anunció que los gastos de la rebelión ascenderían a un millón de pesos con parte de los recursos de las aduanas tomadas por el gobierno del estado.$^{71} \mathrm{~A}$ Sonora se había agregado Sinaloa. El general Ángel Flores realizó avances en su estado natal, por lo que el frente de guerra ya era considerablemente amplio. La lucha no tardó en ser vista como nacional y, desde luego, pasó de la defensiva a la ofensiva. El 15 de abril, el coronel Guillermo Nelson había atacado la estación de San Blas, Sinaloa, que fue abandonada por los carrancistas. El avance de los rebeldes siguió hasta Culiacán, que fue tomada el día $19 .^{80}$

\footnotetext{
${ }^{74}$ Orientación, 10 de abril de 1920, AREM, Cónsul José M. Arredondo (Douglas) al secrẹtario de Relaciones Exteriores, 10 de abril de 1920, LE 866-188.

${ }_{75}^{75}$ Rivera, op. cit., p. 522-523. Hall, op. cit., p. 221. El Universal, 19 de abril de 1920.

${ }^{76}$ Calles a De la Huerta, 9 de abril de 1920, en Valenzuela y Chaverri, op. cit., p. 100.

${ }^{77}$ Archivo General del Estado de Sonora (AGES), ley 30, 11 de abril de 1920, 3367.

${ }^{78}$ Alvarado vivía en el autodestierro en los Estados Unidos, distanciado del Primer Jefe. El 12 de mayo de 1919, Carranza le negó la licencia ilimitada del ejército, siendo más tarde encarcelado por el general Alejo González, jefe de Operaciones de Chiapas, y remitido a la ciudad de México en el carro-caja de un tren. Aquí obtuvo la libertad y se trasladó a los Estados Unidos, desde donde se mantuvo atento y actuante en contra de la imposición del ingeniero Bonillas. José Domingo Ramírez Garrido, "Alvarado, Salvador", en Diccionario tabasqueño: geografia, historia, biografia, bibliografia, algunos datos sobre historia natural, música y curiosidades del Estado de Tabasco, México, [s. e.], 1946, p. 16.

${ }^{79}$ Valenzuela y Chaverri, op. cit., p. 215; El Universal, 13 de abril de 1920.

80 "El Plan de Agua Prieta", en Crónica ilustrada de la Revolución mexicana, 73, Publex, 1968, p. 8.
} 
Este giro se reflejó de inmediato en el terreno político. El manifiesto de los tres poderes de Sonora del 13 de abril amplió las razones del rompimiento con Carranza, en una perspectiva más allá del ámbito estatal. A la vez que recogió las quejas del gobierno del estado ya conocidas, agregó ahora una lista de atropellos oficiales contra el general Obregón en su calidad de candidato presidencial. A las claras este manifiesto reflejó la gama de compromisos políticos que los sonorenses tenían con sus aliados a lo largo y ancho de la geografía nacional. Se acusó al gobierno de Carranza de haber preparado fraudes en las elecciones de poderes locales de Guanajuato, San Luis Potosí, Querétaro, Nuevo León y Tamaulipas. Se criticó la actitud del ejecutivo ante las elecciones del ayuntamiento de la ciudad de México (en alusión a Jorge Prieto Laurens y los cooperatistas), y su participación en el "cuartelazo" de Nayarit contra el gobernador constitucional del estado. Se arremetió contra la disolución, "por la fuerza bruta", del Partido Socialista Obrero de Yucatán y contra los ataques de Murguía y Orozco en Tampico en perjuicio de los obregonistas. Se condenó, por preparar "una burla sangrienta al voto popular", la junta de gobernadores de los estados. ${ }^{81}$

Adolfo de la Huerta sostuvo que él asumió la suprema jefatura del movimiento revolucionario en formación y encargó al licenciado Gilberto Valenzuela y al ingeniero Luis L. León la encomienda de redactar un plan y un manifiesto. Valenzuela acabó entregando el proyecto definitivo y le pidió que se lo entregara a los generales Calles y Flores y demás jefes militares para su firma, cosa que así ocurrió ${ }^{82}$ Desde Agua Prieta, Calles habría dado su consentimiento al plan en todas sus partes y pidió que fuese promulgado en esta población: "Me sentiría satisfecho de que el plan llevara el nombre glorioso de mi 'república': Agua Prieta [...] si el plan es firmado en esta población [...] Agua Prieta vivirá para siempre en la historia de México." ${ }^{83}$ El documento original sería llamado Plan de Hermosillo, "cambiando de nombre por el de Agua Prieta el 23 de abril a iniciativa del general Calles". ${ }^{84}$ En todo caso, y seguramente para conservar las formas, en una comunicación solemne, De la Huerta señaló

${ }^{81}$ Manifiesto de los tres poderes al pueblo de Sonora, Hermosillo, 13 de abril de 1920, en Valenzuela y Chaverri, op. cit., p. 213-215. Orientación, 13 de abril de 1920.

${ }^{82}$ Rivera, op. cit., p. 524-526.

${ }^{83}$ Valadés, op. cit., p. 44-45.

${ }^{84}$ Adolfo de la Huerta, Resumen biográfico..., op. cit., p. 5. Don Gilberto Valenzuela confirma el dicho de De la Huerta: "Yo hice el plan, yo lo llamé Plan de Hermosillo, Calles estaba en Agua Prieta y me mandó a Luis León, Calles, a ver, a platicar conmigo a ver si le mandaba yo una copia del plan, yo inmediatamente le mandé una copia del plan; yo le llamaba Plan de Hermosillo, y lo convocó Calles, entonces se llamó Plan de Agua Prieta..." [transcripción 
haber "estudiado detenidamente el Plan de Agua Prieta y estimado que tales prescripciones de índole político-administrativa contenidas en dicho documento se inspiran en la justicia y la moralidad [...] y corresponden a la situación por la que atraviesa la república". A continuación consideró su "deber aceptar el cargo de jefe supremo interino del Ejército Liberal Constitucionalista que se me confiere en el documento citado, y para los efectos correspondientes protesto solemnemente sostener dicho plan en todas sus partes y desempeñar con fidelidad y patriotismo el cargo con que he sido honrado". Finalmente, hizo un reconocimiento "a todos los ciudadanos que firmaron el Plan de Agua Prieta por la distinción con que me favorecen". ${ }^{85}$ Durante la discusión del plan, dos posturas se enfrentaron con respecto al nombramiento, a partir de un acuerdo de subordinación a las autoridades civiles, en este caso De la Huerta. Unos sostuvieron que éste debía ser nombrado jefe de manera definitiva, mientras que Calles argumentó que sólo debería asumir el puesto de manera interina, en tanto los delegados de los gobernadores constitucionales de los estados que reconocieran el Plan de Agua Prieta, lograban reunirse para nombrar de manera definitiva al jefe supremo del Ejército Liberal Constitucionalista. Por encima de estos dos criterios, afirmó Calles, estuvo el acuerdo de que fuese un civil la cabeza del movimiento, a fin de que "éste no se tachara de militarista". En esta dirección, "propuse al Congreso que se designara al Gobernador Constitucional del Estado, y de aquí la aprobación de mi idea a la legislatura", según afirmaría Calles. ${ }^{86}$ Adviértese que el Plan se dirigió "a los gobernadores", aunque convocó en efecto a todos los enemigos activos del carrancismo. "Tengo la seguridad de que la designación del jefe supremo definitivo [...] le dará a quien resulte electo mayor prestigio y autoridad mayor", era la opinión de De la Huerta ${ }^{87}$ Podría pensarse, como una de varias posibilidades, que esta postura abría las puertas para que Obregón, ya rota la institucionalidad política del país, llegase ocasionalmente a ocupar tal puesto. Resulta de particular interés que De la Huerta, a pocos días del lanzamiento del Plan de Agua Prieta,

textual] . Entrevista con don Gilberto Valenzuela, realizada por Linda Hall y Ma. Alba Pastor, el día 11 de julio de 1974. México, Archivo de la Palabra del Instituto de Investigaciones Dr. José Ma. Luis Mora, $\mathrm{PHO} / 4 / 42$, p. 37.

${ }^{85}$ Fideicomiso Archivo Plutarco Elias Calles y Fernando Torreblanca (APEC), De la Huerta (Hermosillo) a Calles (Agua Prieta), 20 de abril de 1920, inventario 1379, expediente 56, legajo 3/10, f. 136-137.

${ }_{86}$ El Universal, 8 de marzo de 1920.

${ }^{87}$ Corresponsal de guerra en Agua Prieta, 24 de abril, en Valenzuela y Chaverri, op. cit., p. 288-289. 
haya enviado una circular a "los miembros del Ejército Liberal Constitucionalista" en la que se definía el alcance del movimiento y el marco legal en que éste se encontraría. "El Plan Orgánico " reconocía como ley fundamental a la Constitución de 1917, y el ejército rebelde se regiría por la Ordenanza General y leyes militares. Bajo tal concepto, y puesto que el artículo 22 prohibía la pena de muerte a los reos políticos, dispuso que los miembros del Ejército Liberal Constitucionalista cuidarían de no infringir tal disposición constitucional, "y todos los prisioneros de guerra y particulares que aparezcan como presuntos responsables de delitos conectados con el movimiento, debían ser puestos a disposición de la Jefatura Suprema". Esta circular es interesante por dos razones. La primera porque expresaba una convicción en favor del respeto a la vida de los enemigos, rasgo que distinguiría a Adolfo de la Huerta a lo largo de su carrera política. La segunda, derivada de la anterior, es que tal decisión se repetiría durante la llamada rebelión delahuertista de 1923.

El 23 de abril de 1920, el Plan de Agua Prieta fue proclamado solemnemente en la plaza del mismo nombre. Recogió en lo fundamental lo que había sido planteado por el manifiesto de los tres poderes. Fue netamente "sonorense", a juzgar por las $107 \mathrm{fir}$ * mas que en él aparecen, con la excepción del general Ángel Flores. ${ }^{89}$ Dio cauce e impulso a un movimiento militar que ciertamente ya había estallado en Sinaloa (15-19 de abril), con Pascual Ortiz Rubio en Michoacán, Enrique Estrada en Zacatecas ( 15 y 16 de abril) y el general Carlos Green en Tabasco (abril 28), todos ellos connotados obregonistas. Como lo hace notar Álvaro Matute, a la vista le salta un añejo sabor decimonónico. Poca diferencia, dice, podría encontrarse entre éste y otros planes que llevaron al poder a hombres como Paredes Arrillaga, Santa Anna y Porfirio Díaz. Se parece al del Hospicio como puede parecerse al de Ayutla o de la Noria, y guarda aspectos en común con el de Guadalupe. ${ }^{90}$ En virtud de él, se desconocía al presidente Venustiano Carranza, a los funcionarios públicos que accedieron a su puesto en virtud de las elecciones lo-

\footnotetext{
${ }^{88}$ Circular de Adolfo de la Huerta, Jefe Supremo Interino del E.L.C., 26 de abril de 1920, en ibid., p. 293-294.

${ }^{89}$ El general Calles, por intermedio del general Roberto Cruz, invitó a Flores a unirse al movimiento. Las autoridades de Sinaloa apoyaban a su rival, el general Juan Carrasco, para gobernador del estado, por lo que su situación era insostenible. Fue nombrado jefe de la Primera División del Ejército Liberal Constitucionalista con Sinaloa como su área de operaciones. Fernando López Portillo, "El general Calles, comandante militar del estado, se dirige al general Diéguez", en El Sol de México, 26 de noviembre de 1968.

${ }^{90}$ Matute, op. cit., p. 109.
} 
cales de Guanajuato, San Luis Potosí, Querétaro, Nuevo León y Tamaulipas, y a los concejales del ayuntamiento de la ciudad de México. Se reconoció a la Constitución de 1917, a José Santos Godínez como gobernador de Nayarit y a "las demás autoridades legítimas de la Federación y de los Estados”. El gobernador De la Huerta fue nombrado jefe interino supremo del Ejército, con facultades para la organización militar, política y administrativa del movimiento. Se convocó a los gobernadores que se adhirieran al movimiento a que nombraran un representante con voto en la designación del jefe supremo del Ejército Liberal Constitucionalista. Pero si no formase mayoría, el jefe supremo definitivo sería Adolfo de la Huerta. A la ocupación de la ciudad de México se nombraría un presidente provisional de la República por designación del Congreso, quien convocaría a elecciones para los poderes ejecutivo y legislativo de la Federación. El jefe supremo nombraría a gobernadores provisionales de Guanajuato, San Luis Potosí, Querétaro, Nuevo León y Tamaulipas, y en los estados que tuvieran gobernador o donde los mandatarios combatieran o desconocieran el movimiento. A la hora del triunfo, los gobernadores provisionales deberían convocar inmediatamente a elecciones de poderes locales. ${ }^{91}$

Su éxito fulminante evitó que la junta de gobernadores rebeldes a que aludía el documento tuviera lugar, cuestión menor porque el liderazgo sonorense contra Carranza era incuestionable. El movimiento de Agua Prieta, afirmaría don Adolfo, no fue resultado de ningún pacto premeditado entre Calles, Obregón y De la Huerta. Una evidencia circunstancial a considerar, por ejemplo, es- el simple hecho de que en el momento del manifiesto de los tres poderes sonorenses (es decir, el paso previo a la rebelión), la situación era particularmente crítica para Obregón, quien se encontraba al pendiente del proceso Cejudo que se seguía en su contra, teniendo a la ciudad de México por cárcel, y ante la sólida posibilidad de ser aprehendido de un momento a otro. El 11 de abril, día del encuentro "casual" con el general Pablo González en Chapultepec, recibió noticias de Calles, quien le avisó que Sonora se aprestaba a defender su soberanía. Alojado en casa de Miguel Alessio Robles, Obregón se quejó: "Adolfo y Plutarco deben tener buenas razones para proceder como lo están haciendo, pero nosotros estamos aquí en la ratonera" ${ }^{92}$ Obregón, según versiones, incluso pensaba que lejos de ayudar esta situación a su causa, era una farsa tramada por el gober-

\footnotetext{
${ }^{91}$ Rivera, op. cit., p. 524-526.

92 Hall, op. cit., p. 224.
} 
nador de Sonora y el presidente de la República, para involucrarlo y dar pretexto para eliminarlo. De la Huerta, en cuanto pudo, le explicó a Obregón la realidad de sus problemas con Carranza y el asunto allí terminó. ${ }^{93}$ Sin embargo, De la Huerta argumentó que había una prueba de mayor peso. Mientras en Sonora se promulgaba el Plan de Agua Prieta, Obregón lanzaba otro con diferentes postulados, una vez que logró la adhesión del general Fortunato Maycotte, entonces jefe de operaciones en Guerrero. ${ }^{94}$ Don Adolfo se refería al llamado Plan de Guerrero, redactado por Fernando Iglesias Calderón y Francisco Figueroa entre otros. En virtud de este plan, se desconocía a Carranza como presidente y a la Constitución de 1917 y se proclamaba la vuelta a la Carta Magna de 1857. Asimismo, se ratificaron las promesas de una ley agraria y de un régimen acorde con una idea del obrerismo. Pero el Plan de Guerrero quedó en el olvido. Cuando el movimiento de Agua Prieta avanzó con más prisa que el del sur que dirigía Obregón en persona, éste prefirió el Plan de Agua Prieta -que no había suscrito-al suyo propio. ${ }^{95}$ Ya en el manifiesto de Chilpancingo del 30 de abril, Obregón declaró la imposibilidad de continuar la campaña política, por lo que era "indispensable empuñar de nuevo las armas, para reconquistar, con las armas en la mano, lo que con las armas en la mano se trata de arrebatar". Poco más adelante, declaraba suspendida la lucha política,

y siguiendo la vieja costumbre de servir a mi Patria cuando sus instituciones están en peligro, me improviso nuevamente en soldado, y al frente del Gran Partido Liberal [...] me pongo a las órdenes del gobernador constitucional del Estado Libre y Soberano de Sonora, para apoyar su decisión y cooperar con él, hasta que sean depuestos los Altos Poderes... ${ }^{96}$

\footnotetext{
13 “Carranza, friend and foe!", op. cit., p. 22. Miguel Alessio Robles señaló que "el candidato presidencial se quejaba conmigo de la actitud del general Calles, que había renunciado a la Secretaría de Industria para ir a encerrarse en Sonora, y allí violentar ese estado de cosas con el fin de que el gobierno federal encontrara motivos suficientes para encarcelarlo. De esa manera el general Calles se aprovecharía de una situación política que el candidato presidencial ya consideraba hecha". Alessio Robles, op. cit., p. 44. Obregonistas como Francisco Serrano, Francisco Manzo y Ramón Ross llegaron a pensar que De la Huerta y Calles en esos días se confabularon para eliminar a Obregón. AGN/OC Dr. Atl (Gerardo Murillo) a Obregón, 20 de mayo de 1921, 1882a-104A.

${ }^{94}$ Adolfo de la Huerta, Resumen biográfico..., op. cit., p. 5.

${ }^{95}$ José Vasconcelos, La tormenta: segunda parte de Ulises criollo, 7a. edición, México, Ediciones Botas, 1948, p. 571-572.

96 Reproducido en Mario Contreras y Jesús Tamayo, México en el siglo XX, 1913-1920: textos y documentos, México, UNAM, 1983, p. 377-378.
} 
En su novelesca huida, y dado el férreo control del telégrafo por Mario Méndez, resulta improbable que el manco de Celaya supiera los pormenores de lo que ocurría en Sonora, aunque es de imaginarse su convicción de que los acontecimientos violentos se precipitarían de un momento a otro.

El asunto del delito de rebelión de Obregón terminó con los acontecimientos posteriores y pasó al olvido. Pero existen elementos que nos pemiten afirmar que el candidato en campaña tejió, a lo largo de su campaña, el entramado de una amplia conspiración capaz de alcanzar sus propósitos frente a la posibilidad real de que las elecciones le fueran desfavorables, dado el empecinamiento de Carranza en su contra. Hacía y consolidaba alianzas en forma directa o a través de sus partidarios más cercanos, y hablaba con jefes militares con mando de tropas. A todos sus interlocutores les hacía ver que era necesario evitar una "imposición planeada" y deberían estar presentes ante cualquier circunstancia. ${ }^{97}$ De manera más discreta, mantuvo tratos con los rebeldes anticarrancistas - pelaecistas, felicistas, serranos oaxaqueños, mapaches chiapanecos, zapatistas morelenses-, que afirman la tesis de que Obregón planeaba su propio movimiento armado, con conocimiento de Calles y De la Huerta, pero que las presiones fallidas del presidente Carranza precipitaron los acontecimientos y dieron como resultado el movimiento de Agua Prieta.

El movimiento fue pronto torrente incontenible. El 5 de mayo, Carranza lanzó su Manifiesto a la Nación. En esta especie de testamento político, hizo una lúcida exposición de los últimos acontecimientos políticos. Aquí habló de que aceptó la postulación a la presidencia por haber considerado que con ello ayudaría a la consolidación de la obra revolucionaria y porque en aquellos momentos el Partido Constitucionalista amenazaba dividirse en dos bandos militares. Carranza estimaba que hasta fines de 1919 la campaña política se desarrollaba solamente entre dos candidatos (Álvaro Obregón y Pablo González), que hacían descansar su triunfo en el apoyo que a su tiempo pudieran prestarles las fuerzas militares que simpatizaban con uno u otro. Por tanto, "la idea de un candidato civil surgió como una posible transacción entre las dos ambiciones militaristas, hasta convertirse en una tendencia política bien definida". Justificaba la idea de un candidato civil como un preventivo contra la "amenaza de la guerra civil y el caudillaje". Protestó sus "garantías de neutralidad" durante el proceso, a pesar de la campaña de despres- 
tigio contra Bonillas, promovida por los obregonistas y los gonzalistas. Analizaba la cuestión electoral, cuyo objetivo ideal había sido llevar a cabo la transmisión pacífica y "democrática" del poder, pero que los procedimientos a que habían recurrido Obregón y González envolverían a la nación en un conflicto armado, ya que sus campañas no habían sido de carácter electoral sino de "una provocación a la revuelta". Carranza denunció las maquinaciones de Obregón para hacerse del poder por la fuerza, la forja de sus alianzas con los rebeldes al gobierno y la orquestación de un amplio movimiento militar encabezado por él mismo. Para él, la sublevación de Sonora era un movimiento "precipitado, prematuro e injustificado" con el pretexto "de una imposición dos meses antes de las elecciones". Para él, la fuga de Obregón el 13 de abril fue "una señal convenida" para que "los levantamientos militares comenzaran a efectuarse", como los del coronel Pascual Ortiz Rubio, el general Enrique Estrada y el general Green, un indicio más de que existía un acuerdo previo, "bien determinado para levantarse en armas, cuando el general Obregón lo hiciera". Después de exponer estos puntos destacó la imposibilidad de que pudieran celebrarse las elecciones presidenciales y dijo que no entregaría el poder ni a Obregón ni a González, sino que continuaría al frente del ejecutivo hasta que la rebelión de los generales fuera dominada y se designara legalmente a su sucesor..$^{98}$

El rey viejo, empero, se había quedado casi solo. El general Pablo González, militar siempre fiel a Carranza, abandonó en definitiva a su jefe el 4 de mayo. Quedaban pocos generales con mando de tropas. El general Francisco Murguía, que estaba en Tampico, se dirigió a la capital de la República para ponerse al frente de los pocos leales. El general Cándido Aguilar contaba con un puñado de fieles veracruzanos. Y el general Diéguez, quien detendría el paso de los aguaprietistas en la costa del Pacífico, no atinaba a actuar, a pesar de su lenguaje belicista. Pasmado por el curso vertiginoso de los acontecimientos, voluntaria o involuntariamente retrasó el prometido avance de sus tropas hacia el noroeste, y pronto fue aprehendido por sus propios hombres, encabezados por el coronel Isaías Castro. ${ }^{99}$ Ante tal situación, Carranza preparó la instalación de su gobierno en Veracruz, apostando a su buena suerte de 1914. La mayor parte de los empleados ferrocarrileros favorecían a

\footnotetext{
${ }^{98}$ Manifiesto a la Nación del presidente Venustiano Carranza, en Contreras, op. cit. p. 379-394; El Universal, 7 de mayo de 1920.

${ }^{99}$ Hall, op. cit., p. 228.
} 
Obregón; sin embargo, un conjunto de trenes del Ferrocarril Mexicano, incluido el Dorado Presidencial y su absurdo burocrático, salieron de la capital el 7 de mayo de 1920. Ese mismo día la capital fue ocupada por las fuerzas de los generales Pablo González y Jacinto B. Treviño, desde el retiro temporal en Texcoco. El Congreso discutió acerca de la situación legal del poder ejecutivo y de la complejidad del momento histórico que vivian. Concluyeron que, al haber desaparecido los poderes ejecutivo y judicial, tendrían que tomar medidas para que Carranza saliera del territorio nacional y la Comisión Permanente nombraría al presidente provisional. Mientras tanto, el general Pablo González instaló un gobierno provisional sin presidente, haciendo nombramientos en distintas secretarías y dependencias de gobierno. El 9 de mayo, Obregón entró a la capital como un César regresando de las Galias, en medio de vítores, aplausos y la admiración de una capital ya acostumbrada a este tipo de paradas. Acto seguido, convocó a una junta de generales para discutir el asunto de la sucesión legal del siguiente presidente de México. Entre los asistentes estaban Pablo González - que no reconocía el Plan de Agua Prieta aunque tenía el control de la capital-, Samuel de los Santos, Fortunato Maycotte, Daniel Ríos Zertuche y otros 16 militares de alto rango. González sostuvo que el objetivo había sido alcanzado con el derrocamiento de Carranza y que ahora seguiría someter el Plan a la consideración de los poderes legislativo y judicial, y pedir a De la Huerta que a su vez solicitara al Congreso la designación del presidente provisional. En una declaración, los militares de común acuerdo manifestaron que "la legalidad y la unificación de los líderes revolucionarios estaban aseguradas", y mandaron un mensaje a De la Huerta con los detalles de su decisión, ${ }^{100}$ a lo que no hubo objeción.

El 24 de mayo de 1920, Adolfo de la Huerta, en su calidad de jefe del Ejército Liberal Constitucionalista, expidió en la ciudad de Hermosillo un decreto en el que se daba el siguiente paso en la transición presidencial. Se establecía que el Congreso, en el periodo de sesiones extraordinarias a que había sido convocado, se ocuparía exclusivamente de designar al presidente provisional de la República. Asimismo, se especificaba que desde la fecha de promulgación del Plan de Agua Prieta, Carranza había cesado en el ejercicio del poder ejecutivo. Con respecto al poder legislativo, el Plan de Agua Prieta no reconocía jurisdicción, ni facultad alguna a la Comisión Permanente, $y$, por lo que se refería al Congreso, sólo se le aceptaba

${ }^{00}$ El Universal, 13 de mayo de 1920. 
la facultad de nombrar presidente provisional. Por último, se comunicaba a la opinión pública el aplazamiento de las elecciones presidenciales para el 5 de septiembre.$^{101}$ Aquel mismo día, en la ciudad de México, las cámaras de Diputados y Senadores se reunieron con el propósito de nombrar a un presidente interino que se hiciera cargo del poder ejecutivo del 1 de junio al 1 de diciembre de 1920 . Para sorpresa de nadie, el resultado de la votación favoreció a Adolfo de la Huerta, quien obtuvo 224 votos contra 29 para Pablo González, uno para Fernando Iglesias Calderón y uno para Antonio I. Villarreal. ${ }^{102}$ Después de un largo periplo primero en barco y luego en ferrocarril desde Hermosillo, De la Huerta tomó posesión de su cargo, y con ello se marcó el fin del periodo carrancista y el inicio de la supremacía del triunvirato sonorense.

\section{Palabras finales}

El ascenso de Adolfo de la Huerta a la presidencia, tal y como se había planteado desde el principio por la organización del movimiento de Agua Prieta, sería por breve tiempo, a fin de preparar las condiciones para la reanudación del gobierno normal de la República. La mecánica del entendimiento con Obregón y Calles funcionaba bien hasta ese momento, favorecida en mucho la voluntad de De la Huerta de regresar a su estado natal una vez que su periodo administrativo hubiera concluido. El caudillo, firmemente entronizado tras el ejército como última razón política, se sabe el mayor beneficiario de la rebelión sonorense y actúa en consecuencia. Mantiene una calculada relación de cooperación y conflicto con De la Huerta, delimitada acaso por una necesidad de influir al máximo y ceder lo menos posible, con miras al futuro próximo en el que, por fin, llegaría a la presidencia. Parte de ese futuro en marcha era la edificación impostergable de un nuevo orden basado en un amplio consenso de las principales fuerzas políticas, algunas de ellas recién salidas de largas confrontaciones con el carrancismo. En ello, la pacificación total del país era tarea principal, a la que De la Huerta dedicó sus mayores esfuerzos desde el inicio del interinato, hasta entregar el mando a su sucesor antes de que concluyera el año de 1920. Había que trabajar, además, en otras labores que redunda-

${ }^{101}$ De la Huerta al presidente del Congreso, en El Universal, 23 de mayo de 1920.

${ }^{102}$ El Universal, 25 de mayo de 1920. 
rían en la mayor legitimidad del grupo sonorense en el poder, tanto en el plano nacional como internacional: la normalización de las relaciones con el exterior, principalmente con los Estados Unidos; la reorganización del ejército, la reconstrucción de las finanzas públicas, la preparación de las elecciones, la recuperación hasta lo posible de los beneficios del petróleo, entre otras tareas. No fue entonces casual que en la propaganda obregonista aparecieran por delante los logros en el sentido apuntado, en los que De la Huerta, una vez más, fue protagonista principal.

$\mathrm{El}$ historiador honrado, cada vez que hace memoria de los acontecimientos pasados, desafía por este solo hecho la verdad establecida. En la medida en que aporta nuevas evidencias e interpretaciones, plantea dudas y siembra confusiones, conmueve con su trabajo los cimientos de lo eterno. Desde la soledad de su gabinete es un aniquilador de escenarios, un profanador de tumbas, un dinamitero de monumentos, un destructor de íconos y, desde luego, un irreverente; todo ello más por necesidad que por voluntad. El estudio que presentamos arrojó como resultado final que hay buenas razones para pensar que ni De la Huerta era un títere "transitorio" al servicio de sus paisanos, ni Obregón realizaba geniales hazañas políticas más allá de la proporción humana. Por fortuna no todas las evidencias se destruyen por completo. Y ellas nos sirven de medios para desmitificar o desatanizar, según el caso, a los personajes y sus acciones. 